\title{
Procedure Agent Modified Reported
} Name

National Cancer Institute

\section{Source}

National Cancer Institute. Procedure Agent Modified Reported Name. NCI Thesaurus.

Code C162120.

An indication or description of a change in a procedure agent name. 